\title{
Situación, estrategias de formación y apuntes sobre la vida íntima de los militares colombianos hacia 1930'
}

\author{
Circumstances, lining up strategies and some issues \\ about colombian soldiers' intimate life around 1930
}

Adolfo León Atehortúa Cruz²

El presente artículo propone una exploración sobre cuatro aspectos para el Ejército colombiano anterior a 1930: su estado real, la influencia de políticos y curas, algunas estrategias de formación y la vida íntima de los militares. Sus deducciones son propuestas con base en una importante revisión de archivos.

Palabras clave

Ejército de Colombia, hegemonía conservadora, militares.

Abstract

The present article proposes an exploration on four aspects of the Colombian Army previous to 1930: its real state, the influence of political and priests, some strategies for lining up and the intimate life of the military. Their deductions are proposed with base in an important and meticulous revision of files.

Keywords

Colombian Army, hegemony, conservatism, military.

Artículo recibido el 14 de febrero de 2009 y aprobado el 28 de abril de 2009.

1 Situation, strategies of formation and point about the intimate life of the military ones, before $1930 \dot{i}$ ?

2 Profesor titular del Departamento de Ciencias Sociales de la Universidad Pedagógica Nacional. Correo electrónico: adolfoatehortua@cable.net.co 


\section{Presentación}

En 1930, el Ejército de Colombia contaba con cinco brigadas, cuyos comandos se ubicaban en Bogotá, Barranquilla, Cali, Medellín y Bucaramanga. Cada una de ellas contaba con tres batallones de infantería, algunas con un Grupo de Caballería o de Artillería y unidades de ferrocarrileros o zapadores.

Sin embargo, tal existencia y distribución era en realidad teórica. Las Brigadas carecían del número de efectivos necesarios para merecer tal título. Su dotación y armamento se basaba en fusiles, la mayoría en regular estado de funcionamiento, y no contaban con armas propias para una guerra regular y externa. Las unidades de ferrocarrileros e ingenieros existían de nombre, sin elementos técnicos adecuados ni instrucción suficiente. La localización de las unidades obedecía más a la situación de orden público que a la disposición de defensa nacional frente a un enemigo de frontera, lo cual explicaba la existencia de fuertes batallones en Bogotá, Barranquilla, Cali, Medellín, Bucaramanga y el Líbano, donde se suscitaban repetidas protestas populares o conatos de insurrección, a cambio de escasa o ninguna presencia en la frontera sur del país, en los llanos orientales o en cada una de sus costas. Se trataba, sin duda, de un ejército dedicado a la represión de las movilizaciones populares que se apartaban del cauce impuesto por la hegemonía.

El presente artículo propone una exploración sobre cuatro aspectos para el Ejército anterior a 1930: su estado real, la influencia de políticos y curas, las estrategias de formación y la vida íntima de los militares.

\section{El deplorable estado del Ejército}

En los años veinte, la economía del país no fue boyante. Las dificultades originadas a raíz de la primera guerra repercutieron sobre los créditos, las importaciones y el valor de la moneda. Al reducirse el impuesto de aduana, el gasto público se contrajo en perjuicio del empleo y de la inversión; el presupuesto nacional se afectó y el rubro destinado al Ministerio de Guerra sufrió serias restricciones. En 1920, por ejemplo, los regimientos militares de Cali, Neiva y Manizales suspendieron la celebración del
20 de julio debido al "estado lamentable y vergonzoso del uniforme de los soldados" (El Tiempo, 23 de julio de 1920). El Ministerio decidió suspender el nuevo reclutamiento y continuar con los soldados en servicio para ahorrarse la compra de nuevos equipos y uniformes (Informe del Ministro de Guerra al Congreso de la República, 1925). La artillería, la marina y la ingeniería de guerra carecían en absoluto de elementos para su labor. La Escuela Superior de Guerra, cerrada en 1918 por falta de presupuesto, no pudo abrirse de nuevo en 1922, como lo intentó el presidente, ante la inestabilidad de la economía. Los profesores de la Escuela Militar prestaron su servicio sin sueldo hasta que, en 1922, el primer año del curso general, se declaró en receso y disminuyó el número de cadetes becados (El Tiempo, 20 de julio de 1922). Ni siquiera las vacantes en el Estado Mayor podían llenarse conforme lo pedían los viejos generales. Episodio único en la historia de Colombia fue la sublevación de la guarnición de Tunja, ocurrida en enero de 1922: en protesta por la falta de pagos, los soldados del regimiento Bolívar abandonaron el cuartel, hicieron disparos al aire y se enfrentaron con la policía (El Tiempo, 20 de enero de 1922). Para completar tan desolado panorama, fue descubierto e investigado por el Congreso de la República un turbio manejo sobre los fondos destinados por el erario público para el ejército y la elaboración de municiones 3 .

Durante el transcurso de la hegemonía conservadora, la situación del ejército fue lamentable en muchos aspectos. Diversos documentos de archivo dan cuenta del patético estado en que se hallaba la tropa y del escaso interés que frente a ello demostraban los oficiales y el propio Ministerio. La falta de uniforme y de calzado, el aspecto lúgubre y antihigiénico de cuarteles y dormitorios, convertidos en auténticas pocilgas, la alimentación deficiente y un estado general que rayaba en la miseria eran la característica común de muchos batallones.

3 Véase El Tiempo, 27 de febrero, 9 de marzo, 24 de marzo y 4 de abril de 1923. 
La desnudez del soldado es señalada por doquier. En algunas ocasiones debe acudir al papel periódico para protegerse del frío o abstenerse de salir a la calle por el raído extremo de su uniforme. La dotación de alpargatas conferida al soldado de la época fue suspendida durante varios años. No hay camas, no hay cobijas ni almohadas, no hay toallas ni elementos de aseo.

Las condiciones del alojamiento son tan reñidas con elementales principios de la higiene, que todas las dependencias de la tropa dan la impresión de la miseria y del abandono por la carencia de muebles indispensables y por el deterioro de los que existen.

La tropa viste harapos de telas delgadas en climas rigurosamente fríos y presta servicio nocturno sin abrigo. [...] Marchan a la instrucción con el vestuario destrozado y ha sido preciso muchas veces, después de un aguacero, ordenar que las compañías pasen al reposo en los dormitorios mientras las ropas se secan, porque el soldado no tiene manera de mudarse.

El soldado ejecuta la marcha de ejercicios sobre la planta desnuda de sus pies. La suela desapareció hace mucho y del zapato sólo conserva aquello que cubre la parte superior 4 .

La desidia agravó en diversas circunstancias la difícil condición de los soldados. Para entonces, los comandantes de cada batallón poseían autonomía para manejar el presupuesto de su guarnición y disponer las inversiones conforme a su criterio. La destinación de los dineros tomaba entonces las vías de la corrupción y la indolencia:

El batallón carece en su mayor parte de colchones y almohadas, hay falta de camas y la tropa duerme en el suelo. Las pocas mesas de comedor están en malísimo estado, lo mismo que la cocina de tropa y los calderos. En cambio, se compraron para el

4 Luis Muelle Reyes. “Justicia. Situación técnica y moral en que se hallaba el Ejército el día de la transmisión de mando, 7 de agosto de 1930". Documento confidencial remitido al Presidente Olaya Herrera. Archivo General de la Nación (en adelante agn), Fondo Academia Colombiana de Historia (fach), Caja 04, Carpeta 17, Rollo 3. casino de oficiales una magnífica vitrola, una vajilla lujosa y completa, retratos de los generales Soublette, Reyes y González Valencia y algunas cosas más que costaron, según me informaron, bastante dinero 5 .

Las condiciones higiénicas de los cuarteles deterioraban de manera trágica la salud de los soldados. Abundaban las enfermedades en los sistemas respiratorio y digestivo trasmitidas por contagio, las infecciones generales y las enfermedades de la piel. La alimentación tampoco ayudaba a la salud y menos aún la carencia de agua potable en la mayoría de las instalaciones militares:

La tropa está casi desnuda. No hay vestuario. La confección de los alimentos es mala, pues los calderos están hechos de remiendos y la estufa casi caída, de modo que siempre resulta la comida llena de hollín y con sabor de humo. [...] No hay agua potable, sólo un burro viejo que carga dos barriles de veinte botellas cada uno para proveer a trescientos hombres trayéndola de la fuente que dista cuatro kilómetros del cuartel. La enfermería está en malas condiciones, sin camas ni colchones ni elementos de los más necesarios. Hay epidemia de disentería producida por la mala calidad del agua. Predominan las enfermedades venéreas y afecciones renales ${ }^{6}$.

Los soldados dormían a la intemperie, en el suelo desnudo. [...] El brusco cambio de temperatura, producido por las lluvias frecuentes que caían sobre el piso de cemento en el patio del cuartel, era causa de la neumonía infecciosa que en poco días mató a dieciocho soldados (García, 1916)7.

Cien o más hombres se amontonan unos sobre otros, en recintos que no tienen ventilación y en guarniciones de clima ardiente. El oficial de servicio no puede visitar estos dormitorios durante

5 José María Tobar. “Comandante del Batallón de Tren Soublette, al Ministerio de Guerra, 1916". Archivo General del Ministerio de Defensa de Colombia (en adelante agmdc), Registro 16796.

6 Ibíd.

7 Observación de Laureano García Rojas en el Comando del Regimiento Córdova, acantonado en Santa Marta. 
la noche porque al entrar la atmósfera que allí se respira es nauseabunda 8 .

La corrupción agravó una situación en extremo complicada. Tenía lugar en los pequeños y bajos planos de la administración, pero también en los más altos. Los libros de contabilidad no existían o estaban "llenos de falsedades y errores". Los elementos de cuarteles, ranchos y casinos desaparecían sin que fuera posible detectar al responsable9. Las crías del ganado militar se convertían en propiedad de los oficiales de remonta ${ }^{10}$. El lucro particular usufructuaba la economía de los batallones y atentaba contra las raciones del soldado. Según el Coronel Alejandro Uribe:

\begin{abstract}
Algunos oficiales no quieren comprender que su misma categoría los obliga a ser buenos y juzgan que, por el contrario, el grado los autoriza para dar malos ejemplos, para ser antihumanitarios, para descuidar al conscripto y aún para arrebatarle el pan. Es ésta una de las causas del terror al servicio militar y del odio al ejército ${ }^{11}$.
\end{abstract}

El oficial subalterno, el suboficial y el soldado, eran forzados a firmar recibos de pago cuya especificación era falsa. Según Paul Gautier, las disposiciones gubernamentales para el manejo del dinero en las guarniciones militares se prestaban para que muchos oficiales cometieran "actos de indelicadeza, reprobados teóricamente pero no castigados prácticamente" 12 .

La contabilidad del Ministerio fue recusada por los medios de prensa y el Congreso en diversas ocasiones. La compra de armamento, vituallas y uniformes, la adquisición de elementos para la aviación, la marina o la caballería del ejército, así como diversos contratos celebrados desde la cartera de guerra,

8 Muelle, fol. 100, p. 32 del documento.

9 Tobar, Registro 16796.

10 Muelle, fol. 118, p. 50 del documento.

11 Alejandro Uribe G. "Labor que es necesario realizar en el Ejército". Documento confidencial remitido al Presidente Olaya Herrera en agosto de 1930. agn, fach, Caja 04, Carpeta 17, Rollo 3, fol. 184, p. XVII del documento.

12 Paul Gautier. "Informe sobre el Estado del Ejército". Documento confidencial remitido al Presidente Olaya Herrera, agn, fach, Caja 04, Carpeta 17, Rollo 3, fol. 158, p. 12 del documento. fueron cuestionados por la falta de honorabilidad o por la ignorancia militar con que se realizaron. Una de las inversiones más criticadas, por ejemplo, fue la compra de maquinarias para la producción nacional de municiones. En razón del alto presupuesto destinado a ellas y al enorme valor de los insumos, los costos de fabricación resultaron tres veces más onerosos que la importación, con una calidad mucho más baja13. Al final, en 1932, sólo "existía un verdadero hacinamiento de vainillas, desperdicios, fierro viejo y cosas por el estilo que daban al visitante una impresión penosa de desorden" (Uribe, 1935, p. 21). Sin embargo, los señalamientos de la prensa, así como las investigaciones del Congreso, sólo obtenían en el mejor de los casos la renuncia o el cambio del ministro.

El atributo de los medios militares descendía con el tiempo. Las armas envejecían y no había nuevas adquisiciones. Según los informes confidenciales recibidos por el presidente Olaya al momento de su posesión, el único armamento efectivo del Ejército consistía en una dotación de fusiles Mauser, modelo 1912, y en un centenar de ametralladoras Lewis. Los primeros se hallaban al borde extremo de su conservación, "a punto de partirse en pedazos por su uso diario intenso"; las últimas sólo servían "para estudiar en ellas los inconvenientes técnicos que hacen nula una ametralladora" 14.

La artillería contaba en total con dos baterías de montaña que habían sido donadas por particulares luego de los sucesos de La Pedrera, en 1912. Aunque sus condiciones técnicas no se discutían, la irrisoria cantidad de piezas que la componían dejaba en claro la "penuria del Ejército". ¿Cómo asistir a un combate con sólo ocho cañones?, se preguntaban

13 Consciente de la autonomía y del grado de rebeldía que importantes sectores sociales cobraban en política por medio de la huelga y de los movimientos populares, Ospina dirigió las inversiones militares hacia imperiosas necesidades del momento. Una de sus decisiones consistió en contratar con la Western Cartridge Company cuatro millones de cartuchos y enviar dos funcionarios para perfeccionar conocimientos en la manufactura de los mismos, así como en la producción de herramienta para esta labor. Luego se contrató al norteamericano Victor L. Davis como técnico especialista, pero se fracasó de manera rotunda cuando se intentó producir la misma munición en Colombia.

14 Muelle, fol. 83, p. 15 del documento. 
algunos oficiales. En respuesta, opinaban que sólo servían para el uso que tenían: "rodar en todas las procesiones y en todos los entierros".

Una comparación contundente, que devela al mismo tiempo el grado de corrupción en el Ejército, es presentada en un documento analítico entregado por el Mayor Silva Plazas a su regreso de Chile:

En el Ecuador, el presupuesto total de la nación es de doscientos millones de sucres, es decir, que reducido a moneda colombiana es apenas el presupuesto de guerra nuestro en 1927 . Sin embargo, allí tienen todas las categorías de establecimientos de instrucción militar, mantienen una numerosa misión italiana, tienen buen número de oficiales en el extranjero y han logrado dotar a todas sus unidades de armas automáticas, material moderno de comunicaciones y de todos los elementos que exige la táctica moderna. En cambio nosotros, que hemos tenido hasta catorce millones de presupuesto, no tenemos sino media docena de ametralladoras viejísimas, cuatro cañoncitos $-\mathrm{y}$ eso porque nos los regalaron-15.

La preparación militar no era tampoco la más apropiada en las filas del Ejército. Atentaban contra ella la falta de presupuesto y de elementos adecuados. No había munición suficiente para las prácticas de tiro, tampoco fusiles idóneos ni polígonos. Las unidades desconocían por completo la munición de fogueo y los fusiles se reportaban "con el ánima y las partes metálicas picadas por el óxido”. En muchos casos, las instrucciones de infantería no se realizaban por ausencia de reglamentos impresos. No pocas guarniciones y cuarteles adaptados en viejos edificios carecían de campos de ejercicio y deporte. La situación era de tal gravedad que, en algunas ocasiones, los reclutas se licenciaban del servicio militar sin presentar revista o con una instrucción simplemente teórica sobre el armamento y su uso ${ }^{16}$. Muchos contingentes terminaban el servicio militar sin haber disparado nunca su fusil 17 .

\footnotetext{
15 José Miguel Silva Plazas. “Documento privado remitido a la Presidencia de la República, agosto 11 de 1930", agn, fach, Caja 04, Carpeta 17, Rollo 3, fol. 228, p. 1 del texto.

16 Tobar, Registro 16796.

17 Muelle, fol. 104, p. 36 del documento.
}

Finalmente, una mirada al manejo presupuestal de la época, así como a la situación real de las inversiones en el Ministerio de Guerra, permite concluir la débil importancia que el Ejército, desde el punto de vista profesional, alcanzaba para los gobiernos conservadores. En primer lugar, el peso presupuestal del Ministerio no recae sobre las tropas, sobre los cuarteles ni sobre los armamentos. La burocracia administrativa ministerial contaba con salarios nada despreciables. Dos ejemplos, en los casos que fue posible establecer, parecen significativos. El Capellán, en cualquiera de las unidades del Ejército, tenía un salario cercano, igual o a veces superior al devengado por el Director de las Normales Nacionales. Un aspecto ligeramente indicativo de la importancia superior que para el régimen ostentaba lo religioso sobre la educación y lo laico. Sin embargo, mucho más asombroso es que el salario del portero del Ministerio de Guerra se equiparó siempre al de los profesores de la Facultad de Derecho de la Universidad Nacional de Colombia y superó la asignación recibida por el profesor-celador de las Normales y el Maestro de Instrucción Primaria. En todos los casos, se trata de un sargento o de un civil, apenas alfabeto, con mejores ingresos que un abogado docente, un normalista docente e interno y un maestro de escuela con conocimientos y responsabilidad superiores.

En segundo lugar, la observación de los salarios de los oficiales del Ejército, su evolución y cambios, señala con nitidez el tacto gubernamental sobre el salario de los altos mandos. A pesar de las reducciones sobre el presupuesto del Ministerio de Guerra y sobre el presupuesto general de tropas, los salarios de los oficiales, aunque pierden en términos absolutos con respecto a 1900, se recuperan positivamente por encima de las deflaciones que padece el gasto central en guerra y tropas. Aunque la tendencia general de la Hegemonía Conservadora entre 1914 y 1925 apuntó a la reducción real sobre los presupuestos de guerra y tropa, el salario de los oficiales no fue considerablemente afectado y, por el contrario, su cantidad registró un aumento importante. Si al lado de ello estimamos la escasa o ridícula inversión en cuarteles y armamento, es innegable que el Ejército 
pudo concebirse más como una fuente de empleos y salarios, sobre todo para altos oficiales, que como aparato de fuerza técnico y profesionalizante ${ }^{18}$.

\section{Políticos y Curas: Una Influencia Determinante}

Tras el triunfo electoral de Olaya Herrera, en 1930, un núcleo importante de oficiales del Ejército consideró propicio el momento para las transformaciones. Aunque algunos podrían acreditar cierta ascendencia liberal en sus familias, no se trataba de oficiales comprometidos con las justas partidistas. Se trataba, sobre todo, de antiguos alumnos de las Misiones Chilenas que estimaban oportuno el ascenso de un presidente liberal, otrora republicano, para depurar al ejército de los viejos vicios de la hegemonía conservadora e impulsar la profesionalización que sus maestros anhelaron.

Este grupo de oficiales era liderado por el Coronel Alejandro Uribe, director de la Escuela Superior de Guerra, y contaba con la aquiescencia de Paul Gautier, profesor de la misma y antiguo miembro de la Misión Suiza, quien se hallaba residenciado en Colombia. De él formaban parte el Coronel Jorge Mercado, el Teniente Coronel Luis María Castañeda y los Capitanes Luis Muelle Reyes y Carlos Matamoros, entre otros. Cada uno de ellos hizo llegar o avaló escritos confidenciales dirigidos al presidente electo, mediante los cuales se analizaba la situación del Ejército y se solicitaban medidas conducentes a la generación de cambios fundamentales en la organización y destino de las fuerzas. Incluso oficiales de marcada simpatía conservadora, como Amadeo Rodríguez, o comprometidos con el régimen de la hegemonía, como Adelmo Ruiz, manifestaron cierto respaldo a sus solicitudes ${ }^{19}$.

Una de las preocupaciones destacadas por los altos oficiales señalaba la intromisión y el poder de la política en el seno del Ejército. Informaban que, si bien la inversión presupuestal presentaba

18 Obsérvese, al respecto, Leyes del Presupuesto General de la Nación, Diarios Oficiales y Documentos Biblioteca Esteban Jaramillo, Contraloría General de la República.

19 Véanse los documentos confidenciales en agn, fach, Caja 04, Carpeta 17, Rollo 3, fol. 64 y ss. un crecimiento sostenido a partir de 1926, el reclutamiento de soldados sólo se efectuaba en zonas con raigambre electoral conservadora. En criterio del Coronel Uribe, los propósitos del ministro Ignacio Rengifo, además de convertir al Ejército en pilar represivo pero también electoral del régimen, apuntaban a crear un cuerpo militar "propicio a su temperamento":

La intriga crece, los ascensos se hacen dadivosos, los piquetes, banquetes y mujeres menudean, el contrato apremia y el ministro, abaluartado en el peligro comunista, hace crecer el presupuesto mientras el ejército carece de dirección y de material, abandona por completo el trabajo, y hasta el servicio de reclutamiento se convierte en propaganda electoral (Uribe, 1935).

El número de oficiales superiores aumenta sin límite porque no hay selección: "se premia su entrega a los políticos". Nuevos oficiales subalternos ingresan a filas sin pasar por la Escuela. Los grados de subteniente, teniente y capitán se convierten en empleos que se ofertan en los directorios políticos conservadores. No importa la incapacidad física ni la falta de preparación. Para "conseguir puestos ventajosos o un ascenso inmerecido", importa la adulación, la intriga y el chisme20:

Los ascensos resultan de la adulación o de la protección y casi nunca como consecuencia de un esfuerzo para mejorar la preparación. No se hacen sino sobre la base del tiempo de servicio cumplido y los pocos oficiales estudiosos son víctimas del odio que profesan ciertos jefes para con aquellos que saben o quieren aprender algo. Este odio defiende la incapacidad notoria de los que ocupan los puestos importantes del ejército y rigen sus destinos ${ }^{21}$.

Del Ministerio salen decretos. Con sorpresa se observa que ciertos oficiales, generalmente conocidos como elementos malévolos, torpes, chismosos y serviles, resultan ascendidos o mejorados de guarnición e impuestos a los comandos y cuerpos de oficiales que intenten rechazarlos.

20 Ibídem, fol. 172, p. V del documento.

21 Gautier, fol. 149, p. 3 del texto. 
Existen nombres que llevan en sí mismos, la marca inconfundible de una protección especial ${ }^{22}$.

Algo similar sucede con los suboficiales. Su presencia en el ejército, sus ascensos y traslados registran el peso de la política. Algunos sólo existen nominalmente, es decir, nombrados para devengar el sueldo correspondiente, pero sin la obligación de aparecer siquiera por el cuartel23.

El apoyo de personas políticas o influyentes constituye garantía de éxito ${ }^{24}$. Se acude a él para ingresar a la Escuela Militar, para garantizar privilegios sobre el alférez, para obtener la asignación del subteniente al arma que desea, para lograr la ubicación del oficial en una unidad militar próxima a sus intereses y para alcanzar los ascensos y destinaciones subsiguientes. La vida militar se impregna de política:

El oficial que carece de influencia es destinado a las guarniciones más alejadas sin que nadie se preocupe de estimular y aprovechar las dotes particulares que muchas veces él posee ${ }^{25}$.

Pero no sólo ello. Según el Capitán Muelle, "el gobierno desconfía de todo elemento que no inspire sus procedimientos en determinadas tendencias partidistas":

Las consecuencias se traducen en traslados a las peores guarniciones, en la denegación de justicia aún en asuntos de elemental humanidad (enfermedades o calamidades domésticas), en la demora indefinida de sus ascensos, en la ausencia absoluta de su nombre para todo aquello que signifique una distinción o mejoramiento, aunque sus méritos lo coloquen por encima de sus compañeros ${ }^{26}$.

Las quejas y denuncias que en su momento elevaron los oficiales ante el presidente Olaya pueden corroborarse con una desprevenida revisión de archivo. Por ejemplo, no son excepcionales las oca-

\footnotetext{
22 Muelle, fol. 113, p.45 del texto.

23 Ibíd., fol. 120, p. 52 del texto.

24 Gautier, fol. 148, p. 2 del texto.

25 Muelle, fol. 109, p. 31 del texto.

26 Ibidem, fol. 110 , pp. 41 y 42 del texto.
}

siones en que un oficial se dirige a otro utilizando el patronímico de "copartidario". Se estila dicho apelativo para solicitar consideraciones especiales con otros subalternos, para invocar la omisión de sanciones o clamar favores por fuera del servicio. Tampoco son excepcionales las recomendaciones de políticos reconocidos para impedir el traslado de un oficial a una guarnición lejana o indeseada. La "lealtad al conservatismo" se recuerda cuando se intenta obtener del Ministerio una prerrogativa o cuando se persigue un ascenso. Haber sido efectivo del ejército gubernamental durante la Guerra de los Mil Días se considera mérito suficiente para justificar cualquier derecho y demandar privilegios 27.

Un caso bastante ilustrativo sucede con el Teniente Marco Duarte, retirado del servicio en 1929 por su "inclinación a la bebida, pernoctar fuera del cuartel y mantener relaciones ilícitas con mujeres públicas". El Teniente presenta ante el Ministerio la recomendación de un congresista, quien certifica que el oficial "es adicto a la causa e hijo de muy buenos servidores de ella". También exhibe la constancia de uno de sus comandantes superiores, quien lo califica como "conservador de sepa, tuerca y tornillo". El Jefe de la Sección de Personal del Ministerio de Guerra ordena agregar copia de estas notas a la hoja de vida del oficial, argumentando que "son honrosas para el señor Teniente Duarte" y poco después se dispone su reintegro a filas. El expediente es nuevamente sometido a estudio bajo la presidencia de Olaya y se subrayan con enorme realce las certificaciones anexas. El nuevo ministro ordena, entonces, su retiro definitivo del Ejército 28.

Las recomendaciones de los curas no son tampoco desdeñables. La práctica religiosa y la asidua asistencia a misa se acreditan para generar confianza entre los superiores. Sirven, sobre todo, cuando el oficial es acusado de llevar una vida impía o de acudir con frecuencia a las "mujeres públicas". Surten similares efectos que aquellas de los políticos. Se utilizan para el ingreso a la Escuela Militar y para evadir traslados enojosos. Se esgrimen para obtener

27 agmdc, Registros 16796, 50342.

28 Ibíd., Registro 37502. 
privilegios o reintegros. Un oficio remitido por un desconocido párroco al Ministro Ignacio Rengifo, así como el resultado que produjo, proporciona una clara muestra sobre el poder influyente de los curas y sobre el destino político que se confiere al Ejército:

Aun cuando no tengo el honor de conocerlo personalmente, convencido de que mi carta tendrá buena acogida, desde luego que nos acerca la misma fe, los mismos principios y que defendemos las mismas instituciones, cada uno en la esfera que la Divina Providencia nos ha designado, no he vacilado en dirigirme a Usted en demanda de un servicio por el cual anticipo mis agradecimientos y le prometo de antemano mi eterna gratitud.

Es el caso que en esta parroquia vive el Capitán Fernando Ponce, persona a quien conozco a fondo y que puedo por tanto garantizarlo como un cristiano celoso por el cumplimiento de sus deberes morales y civiles. Según me ha dicho el Capitán Ponce, se retiró del ejército voluntariamente y ha sido siempre su deseo volver al servicio. Me permito encarecerle el nombramiento de este oficial, quien ya ha hecho la respectiva solicitud en la forma reglamentaria.

Lo recomiendo especialmente porque conozco de manera íntima su modo de pensar acerca de las perniciosas ideas que con tanto perjuicio de la Iglesia y de la patria nos llenan de pavor. Hoy más que nunca vemos en el Ejército la salvaguarda de la religión, de la patria y de la sociedad. Mas, para que nuestro ejército cumpla con esta augusta misión, es indispensable que su cuerpo de oficiales sea de toda confianza y de principios muy arraigados. Notamos esta selección en sus nombramientos, cosa que nos llena de confianza en Usted, de ahí el porqué de mi atrevida recomendación que Usted sabrá disculpar29.

29 Presbítero Peregrino Segura al Ministro de Guerra Ignacio Rengifo, 18 de septiembre de 1928. agmdc, Hoja de Vida del Capitán Fernando Ponce.
La carta produjo un resultado indiscutible: el Capitán Ponce fue readmitido en el Ejército y se le ascendió a Mayor.

Desde luego, la influencia de la Iglesia en la vida nacional era insoslayable. Para algunos autores, por ejemplo, la intervención del Arzobispo Primado de Colombia, Bernardo Herrera Restrepo, fue definitiva para la creación de la Escuela Militar y la contratación de la Primera Misión Chilena en 1907 (Rodríguez, 1993, p. 311). Pero lo era también para la escogencia presidencial, como operó hasta 1930. En esa fecha, la dirigencia conservadora no tenía un solo candidato: tenía siete. El autoritario arzobispo Herrera había muerto y el nuevo arzobispo primado, Ismael Perdomo, quiso congraciarse con la elite política: reconoció a todos los candidatos como viables y católicos y dejó la escogencia en manos de la mayoría conservadora del Congreso.

Fue un paso en falso. Cada uno de los candidatos sintió que, por primera vez después de muchos años, la elección dependía de sus copartidarios y no de una bendición. Poco después, el arzobispo dejó sentir sus vetos. El primer perjudicado fue el ex presidente José Vicente Concha, cuya candidatura no era grata a Estados Unidos por su posición frente al tratado sobre Panamá. Luego, a solicitud del Congreso, el arzobispo Perdomo renovó sus votos por Alfredo Vásquez Cobo, pero la decisión de un nutrido grupo de conservadores fue proclamar al poeta Guillermo Valencia por encima de las sotanas ${ }^{30}$. El presidente Abadía hizo también su "guiño" por Valencia. No olvidaba que Vásquez Cobo, ministro de guerra de Rafael Reyes, había ordenado su destierro al penal de Acacías, en el Meta.

El partido se dividió y también lo hizo la Iglesia. El arzobispo de Medellín pidió apoyar a Valencia y los curas de pueblo se sintieron autorizados para tener su propio candidato. No obstante, las intrigas del presidente Abadía en Roma hicieron variar la posición del arzobispo Perdomo. Poco después apoyaba a Valencia y pedía la unidad del clero y de

30 La muerte sorprendió a José Vicente Concha el 8 de diciembre de 1929, como embajador de Colombia en Roma. Sus partidarios se plegaron a la candidatura de Guillermo Valencia. 
la Iglesia. Es más, declaró obligatorio para todos los católicos votar por Valencia. Los sublevados, entonces, fueron los vasquiztas. Con el apoyo de ocho obispos, ofrecieron cortarse las manos o votar por Olaya antes que votar por Valencia. Ismael Perdomo cambió una vez más de posición y pidió a Valencia declinar a favor de Vásquez Cobo. Al final, no hubo candidato legítimo del partido conservador y no se pudo derrotar a Olaya. Vásquez, un general retirado con enorme influencia en el Ejército, reconoció de inmediato el triunfo liberal. Como corolario, el poder de la Iglesia, antes omnipotente, empezó a defeccionar sobre el Estado.

\section{Estrategias para modelar conductas}

La Segunda Misión Chilena implantó en el Ejército colombiano un sistema de evaluación semestral sobre los oficiales, que pretendía seguir aspectos como cualidades profesionales, vocación o espíritu militar, aptitudes para el mando, capacidad resolutiva, iniciativa, inteligencia, ilustración, cooperación, perseverancia, resistencia, conducta, disciplina y cumplimiento del deber. Cada seis meses, el oficial superior calificaba a todos los oficiales subalternos bajo su responsabilidad y remitía sus notas a las hojas de vida de cada uno de ellos en el Ministerio de Guerra. El sistema permitía contar con diversas apreciaciones sobre el oficial al momento de su ascenso, pero servía igualmente para centralizar toda la información sobre los oficiales en el Ministerio, forjando un sistema de vigilancia y control bastante eficaz entre los uniformados.

El sistema cumplió, además, un papel fundamental con respecto a la subordinación. El oficial superior notificaba su evaluación al subalterno y obtenía de éste, en forma tácita o concreta, un compromiso de trabajo para mejorar las "fallas" que le eran señaladas. Pero, por otro lado, se convirtió en mecanismo de presión y “depuración” por parte de mayores, coroneles y generales leales a la hegemonía, sobre los cadetes recién egresados, tenientes y capitanes "sospechosos" de mantener simpatías con la oposición al régimen. En este sentido, se agregaron a las evaluaciones otros aspectos como lealtad, trato a los subordinados, porte militar, situación econó- mica y "ejercicio de la religión católica, apostólica y romana”.

Este último tópico se convirtió, precisamente, en punto clave para detectar y diferenciar a los oficiales de ascendencia liberal con aquellos de ascendencia conservadora y obtener o impulsar el retiro de los primeros. Una nota según la cual el oficial superior consideraba que el subalterno "dice ser católico, apostólico y romano pero practica poco los preceptos de la iglesia", podía anteceder la baja del implicado o el aplazamiento de un ascenso ${ }^{31}$. En otras ocasiones, una nota similar, o aquella que advertía el "descuido de los deberes eclesiásticos", servía para que en el semestre siguiente el oficial cuestionado acudiera cumplidamente a misa y practicara confesión, comunión y amistad con el capellán, a efecto de superar cualquier llamado de atención.

Sin embargo, no sólo ello se exigía. También se hacía constar la "indiferencia frente a la religión", "no obligar a sus oficiales a oír misa con la tropa para dar ejemplo", "no inculcar los mandamientos de la religión católica, apostólica y romana entre los soldados" o el sostener "relaciones ilícitas sin pasar por la bendición sacerdotal”. En 1922, por ejemplo, un "comentario poco comedido", que el oficial Agustín Mercado supuestamente hizo sobre "un acto religioso", fue suficiente para solicitar su retiro, el cual fue decretado por el Ministro Ignacio Rengifo años después ${ }^{32}$.

La situación opuesta, asimismo, podía dar envite a la carrera militar. Roberto Perea, el primer cadete en alcanzar el grado de General, recibió felicitaciones por su "constante práctica católica, apostólica y romana", por "cumplir con sus deberes religiosos" y observar una "conducta moral ejemplar dentro y fuera del cuartel". A esas atribuciones se sumaron "un notable amor por la carrera de las armas", "acendradas virtudes de la subordinación y la lealtad" y un "respeto sin tacha por los superiores": "le apasiona el servicio", "es exagerado en el cumplimiento de las órdenes que recibe" y "cumple los mandatos en forma escrupulosa y con buena voluntad" fueron

31 AGMDC, Registro 65562.

32 AGMDC, Registro 55841. 
algunas de las anotaciones que obtuvo entre 1912 y 192733.

Las observaciones lograban eco entre los oficiales inferiores. Tan pronto se les acusaba de algo, la permanencia en el servicio exigía que al semestre siguiente se hiciera todo cuanto tuvieran a su alcance para hacer notar sus propósitos de mejoría. Así se contrarrestaba el "abuso del licor", el "poco entusiasmo por la carrera", el "abandono del estudio", el "escaso conocimiento de los reglamentos", la "pereza", la "seriedad", la "honradez" y la "falta de modales", entre otros. Anotaciones como "le falta energía", "funda su orgullo en exceso de atenciones", "moroso en los trabajos que se le confían", "inclinado al licor", "da molestias y quejas", "poco entusiasta en la carrera", "indiferente y abandonado", "no se interesa por la buena marcha de su compañía", "le falta actividad", "inteligencia apenas regular", entre otras, abrumaban algunas hojas de vida militares. Un año después, las circunstancias cambiaban: "se esfuerza por cumplir", "ha mejorado su voluntad para el trabajo", "es ordenado y trabaja para lograr su cometido", "es prudente y enérgico", "estudia los reglamentos", "es muy aficionado al estudio de la historia nacional" 34 .

No obstante, también se hacía seguimiento a hechos como "criticar las órdenes de los superiores", "hablar de política y sociedades secretas", "criticar a las autoridades", "hablar mal del gobierno", "propalar murmuraciones contra superiores y compañeros", "alardear con mujeres públicas", o "malgastar sus ingresos". En estos casos procedía el confinamiento y la sanción, "formar al oficial antes de ascenderlo" 35, "trasladarlo o retirarlo de las filas":

El Teniente es un inconveniente para la disciplina de esta unidad. Todo lo hace con disgusto o no lo hace. Mucho me temo que de un momento a otro ocurra con él algo grave, dada la situación de rabia que lo domina. Él no respeta a nadie ni en ausencia ni en presencia. Es su índole, su estado normal es

33 AgMDC, Registro 2257.

34 Véase, por ejemplo, AGMDC, Registro 41975.

35 AGMDC, Registro 46897. rebelde en todo y para todo. La obediencia no se ha hecho para él ${ }^{36}$.

En suma, la calificación semestral no perseguía la problematización, cuestionamiento y deliberación en torno a las acciones desarrolladas por el oficial en su proceso de formación. Por el contrario, la verticalidad de los juicios de valor emitidos por los superiores se convertía en patrón o criterio de realidad simplificada en torno al cual se buscaba el control y la sujeción del individuo. La evaluación se orientaba más hacia la construcción de información con el propósito de modelar, clasificar, seleccionar o sancionar, que a la indagación reflexiva, sistemática, rigurosa y ética sobre la realidad, para potenciar su desarrollo.

\section{Aspectos de la vida íntima}

La evaluación también desempeñó un importante papel con respecto a la vida íntima de los militares y su seguimiento. La homosexualidad, en particular, fue sancionada con el retiro inmediato del Ejército, sin que fuera útil la militancia política o la recomendación de algún dirigente conservador ${ }^{37}$. En ciertos eventos, no obstante, el oficial logró aplazar la medida o negar los cargos cuando las pruebas no parecían determinantes. Uno de estos casos ocurrió, precisamente, con uno de los cadetes fundadores de la Escuela. En 1914, una anotación en su hoja de vida sostuvo que:

Decires sordos le hacen algún cargo contra su conducta moral, que se opone a las leyes de la naturaleza, pero no ha habido ni siquiera indicio que permita confirmar esa voz que se oye en el silencio de los fueros internos.

Un año después, en 1915, el mismo superior apuntó que el oficial gustaba "tener relaciones con mujeres públicas sin hacer mayor esfuerzo por ocultarlo" "Es escrupuloso en las horas del servicio y culto con las damas y subordinados". El oficial se retiró voluntariamente en 1923, pero se reintegró años más tarde hasta que, en 1935, fue acusado por

36 AGMDC, Registro 38220.

37 AGMDC, Registro 50545 
una decena de soldados, quienes argumentaron haber sido irrespetados u obligados a sostener con él relaciones sexuales clandestinas. El delatado negó los cargos, pero aceptó haber examinado a algunos de ellos "para verificar si presentaban enfermedades venéreas". Su superior solicitó someterlo a un "Tribunal de Honor Militar", pero el oficial presentó su retiro inmediato 38 .

Al lado de la homosexualidad, a los oficiales superiores y a los sacerdotes les preocupaba el contacto que jóvenes oficiales establecieran con "mujeres públicas”. Destacados en lejanas guarniciones, aislados de sus círculos sociales y familiares, los recién graduados subtenientes acudían con regularidad a escandalosos burdeles para licenciar el estricto acuartelamiento a que eran sometidos durante su formación como cadetes.

En este caso, inquietaba a la institución la indisciplina del novel oficial, la afición por el licor, el mal ejemplo para la tropa y el alto índice de sífilis y enfermedades venéreas existente en los cuarteles. Los capellanes de cada guarnición, a su vez, llamaban la atención por la moral y sancionaban el carácter público que, en ocasiones, asumían los devaneos: "Conducta regular. Entratándose de su vida íntima, tiene poco respeto por sus compañeros. Dice ser católico pero practica poco los preceptos de la iglesia" 39.

Sin embargo, intranquilizaba más la posibilidad real de que algunas de estas relaciones se convirtieran en permanentes:

Vivió algún tiempo frente a los cuarteles con una mujer pública y hacía alardes de poseerla. Se servía de su ordenanza para fiscalizar la conducta de ella. Dice ser católico pero si lo fuera no manifestaría tanta indiferencia en ese sentido ${ }^{40}$.

La unión libre, denominada "relación ilícita", era otro motivo de gran preocupación. A los curas les impacientaba por el "contenido inmoral y pecaminoso", "ajeno a los preceptos católicos y a las

38 AGMDC, Registro 65562.

39 AGMDC, Registro 55841.

40 Ibíd. buenas costumbres" que, en su criterio, contenía dicha relación. A los oficiales superiores, además de lo anterior, les alarmaba el peso que una condición de tal índole ofrecía sobre la carrera militar del joven oficial y sus continuos traslados. Frente a ello, cinco casos hallados en las hojas de vida de diversos militares ilustran las decisiones de los implicados. En primer lugar, se encuentra el oficial que, una vez amonestado, decide romper cualquier vínculo:

Se le recomendó abandonar esa mala causa por ser un inconveniente moral y social. Esto se repitió varias veces: se resta prestigio al Ejército y se ofende a la sociedad. El asunto terminó hace meses. Fue una cuestión pasajera y ya no existe. Hoy el subteniente observa muy buena conducta moral y social. [...] Hago constar que su conducta es muy buena, tanto pública como privada.

En segundo lugar, está el oficial que, por todos los medios, intenta ocultar la situación sin definirla:

Dice el capellán que vive con una mujer públicamente, a pesar de ser amonestado por sus superiores. La causa fue alejada por traslado de ella a Cúcuta a donde el Teniente quería estar viajando.

En este caso, es el Capellán quien se encarga de efectuar el seguimiento e informa al Comandante de la Guarnición:

Había alejado a la concubina pero hay informes fidedignos de que la trajo de nuevo al barrio de Zulia y de que la visita diariamente, de lo cual han dado cuenta las gentes del barrio y empiezan a reclamar contra este estado de cosas.

El propio Capellán pidió al alcalde recibir el testimonio de varios vecinos que dieron cuenta del hecho en actas remitidas al General Comandante de la División. Este declaró que "han sido inútiles las medidas tomadas para la corrección del calificado y que la sociedad y el clero de Pamplona se quejan de la conducta de este oficial". Por consiguiente, solicitó al Ministerio "dictar alguna providencia en este asunto que tanto desdice de los oficiales". La situación concluyó con el retiro del oficial, quien acudió a las recomendaciones de influyentes políticos conservadores para obtener su reintegro. Este 
se obtuvo en 1928 con la promesa jurada de que su relación sentimental había sido liquidada.

En tercer lugar, no falta el oficial que, sin terminar su relación, decide iniciar otra más formal para calmar la ira de superiores y curas:

El capitán traía una mujer con la cual mantenía relaciones ilícitas. Con tal motivo le llamé la atención significándole que era preciso abandonara esta causa, inconveniente desde todo punto de vista, especialmente desde el moral y social, exigiéndole su terminación para el buen nombre del regimiento y el ejército en general. El capitán ofreció poner de su parte los medios para llevar a efecto lo que se le exigía. Días después me significó que como primera providencia, la mujer en cuestión saldría de esta ciudad a otra población y entiendo que así se hizo, pero parece que ella viene en ocasiones a esta localidad, encontrándose aquí en la actualidad. A mi conocimiento no ha llegado noticia alguna de ostensibles escándalos sobre el particular, lo que me hace suponer que el capitán procede con reserva en este asunto. Últimamente he observado que el capitán fomenta relaciones con una señorita con propósito de matrimonio, según parece.

En cuarto lugar, se tiene al oficial que prefiere ser retirado del ejército antes que romper con su amorío:

Se le ha impuesto reprensión simple, arresto de cuarenta y ocho horas, reprensión severa por desobedecer la orden del Ministerio de que ciertos oficiales deben pernoctar en el cuartel, pero ha sido imposible. El oficial continúa dando pésimo ejemplo a sus subalternos y sembrando descontento entre elementos civiles. Su retiro está más que motivado.

Finalmente, aunque menos presente, ocurre el caso del oficial que decide contraer matrimonio. Arrastra, sin embargo, la censura de sus superiores y se le cercena su carrera militar hacia el futuro ${ }^{41}$. El matrimonio, en sí mismo, no era tampoco institucionalmente deseable para los oficiales jóvenes.

41 Sobre los casos en referencia pueden observarse, por ejemplo, los registros 57943 y 37501 en AGMDC.
En criterio de los superiores, el carácter imprevisto y poco planeado de estas uniones importunaba la vida del oficial y truncaba su carrera. A esa edad, plagada de inexperiencia, no existía el juicio ni la sensatez acertadas para la selección de esposa. $\mathrm{Ni}$ el grado ni el sueldo se correspondían con las exigencias del matrimonio y el servicio reclamaba, además, la presencia del oficial de día y de noche con su tropa. Por esa razón, Paul Gautier proponía al presidente Olaya "tratar de prohibir el matrimonio por lo menos a los subtenientes" 42 , en tanto que Alejandro Uribe advertía:

Si bien la ley no puede impedir el matrimonio del individuo, sí puede colocar como condición para ser oficial subalterno que éste sea soltero o, al menos, hacer efectiva la condición del permiso por medio de la cual la autoridad puede celar que el matrimonio llene ciertos requisitos de orden social y militar, y que la novia tenga algunos recursos que impidan malos procederes futuros por parte del oficial ${ }^{43}$.

\section{Conclusiones}

Antes de 1930, la situación del Ejército Nacional en términos de profesionalidad y modernización era realmente crítica. Orgánicamente era un ejército débil, competente para pasar por las armas cualquier conflicto con trabajadores inermes, pero poco apto para enfrentar un enemigo de envergadura en el país o en sus fronteras.

La alta oficialidad no se reputaba entre las más acreditadas de Suramérica. Derrotada la Reforma Militar, la cantidad de oficiales superiores aumentó sin selección y no pocos mandos subalternos ingresaron a las filas sin adelantar estudios en la recién creada Escuela Militar. No obstante, una característica hizo a la oficialidad colombiana particularmente distinta frente a otras del continente: era en esencia conservadora y capitalina, ajena a los entornos e intereses provinciales y de espalda a los confines del país. Los altos mandos no abandonaron sus deferencias para con los notables del régimen

42 Gautier, op. cit., fol. 164 , p. 18 del documento.

43 Uribe, op. cit. fol. 179, p. XII del documento. 
y no vivieron tentaciones ideológicas para romper con los clisés conservadores y clericales. Con la anuencia de los viejos generales, los grados militares se convirtieron en empleos ofertados por los jefes y directorios políticos conservadores bajo la influencia de la iglesia, sin importar la incapacidad física o la falta de preparación. El tráfico de influencias, el clientelismo y el nepotismo, aparecieron en cada ascenso, en cada traslado o nombramiento. El apoyo de políticos y curas constituyó garantía de éxito en la carrera militar.

Con la participación de semejantes mandos, el poder civil pudo extirpar con facilidad cualquier brote reformista entre los jóvenes oficiales. La selección en el ingreso a la Escuela Militar se hizo rigurosa. La extracción social y la recomendación política, las referencias escolares y eclesiásticas, la vigilancia permanente y una fianza onerosa suscrita por la familia, eran suficientes para garantizar el comportamiento de cada alférez. La ascendencia del régimen y del partido se mantuvo sobre los oficiales, cuyo control se reforzó por medio de diversas estrategias para modelar conductas.

La situación general de los soldados y suboficiales en Colombia no estuvo tampoco dispuesta para el apoyo de los pocos oficiales inconformes. A principios del siglo XX, el espíritu de cuerpo y la conciencia militar eran reducidos. En los cantones primaba todavía el espíritu de partido y la influencia religiosa; la devoción frente a los mandos superiores y el respeto al régimen como corolario de la Guerra de los Mil Días.

El servicio obligatorio se asociaba con la mala fortuna o el castigo porque la misma condición de los reclutas era lamentable. El manejo desacertado del presupuesto, la corrupción desaforada en el Ministerio de Guerra, así como el escaso interés que con respecto al Ejército Nacional demostraron los altos funcionarios del Estado, dieron cuenta de

\section{Bibliografía}

Álvarez, V. (Brigadier General) y Giraldo, H. (Mayor). (1997). Escuela Militar de Cadetes General José María Córdova. Noventa años de historia. Bogotá: Litografía Arco. la patética condición en que se condenó a la tropa. La preparación militar no fue tampoco la más apropiada en las filas del Ejército. En forma inverosímil, algunos contingentes de reclutas pasaron por el servicio sin conocer un arma. No había fusiles idóneos para la práctica de tiro, tampoco munición y mucho menos campos de polígono.

Pese a las leyes sobre servicio militar, el reclutamiento continuó efectuándose de acuerdo con las necesidades políticas. Los reclutas fueron sustraídos de las zonas conservadoras cuando se necesitó trasladar su voto de una región a otra, amarrar su decisión electoral o reprimir con éxito la protesta social. En cambio, fueron extraídos de las zonas liberales cuando fue preciso impedir su voto, castigar su militancia o "enderezar" sus conductas.

La explicación acerca de las ambigüedades de la hegemonía conservadora con respecto al proceso de profesionalización de los militares puede encontrar allí su fundamento: el Ejército Nacional fue un elemento más para posar en la balanza de las correlaciones de fuerza e inclinar su fiel.

En ese sentido, los gobiernos centrales se hicieron prisioneros de su propia ambivalencia. Por una parte, insistían en la necesidad de sustraer a los militares de la práctica electoral, pero, por otra, no lograban imponerse sobre los intereses de caudillos y caciques regionales que los atrapaban en su lógica tradicional. Por un lado, parecían dispuestos a aprobar una ley de servicio militar obligatorio, pero, por otro, su voluntad era trascendida por la práctica cotidiana de la política local. Por una parte, se mostraban dispuestos a impulsar la profesionalización entre los uniformados, a contratar misiones extranjeras que impulsaran su formación y los modernizaran, pero, por otra, vislumbraban la conveniencia de un ejército leal a su partido y a su régimen.Дl

Atehortúa, A. (1994). Estado y Fuerzas Armadas en Colombia. Bogotá: Tercer Mundo-Universidad Javeriana. 
Bermúdez, G. (1982). El poder militar en Colombia. De la Colonia al Frente Nacional. Bogotá: Editorial América Latina.

García, L. (1916). Al Excelentísimo Señor Presidente de la República. Pamplona: Imprenta de la Diócesis.

Icenhour, J. (1976). The military in Colombia Politics. Dissertation Ph.D., The George Washington University.

Informe del Ministro de Guerra al Congreso de la República. (1925). Bogotá: Imprenta Nacional.

Leal, F. (1984). Estado y política en Colombia. Bogotá: Siglo XXI Editores-Cerec.

Mury, W. (1975). L'armée colombienne. Etude d'une institution militaire dans ses rapports avec la société en transition, 1930-1974. Tesis de Doctorado, Universidad de París,.

Rodríguez, J. J. (1993). El Ejército del siglo XX. De Reyes a López. La Reforma Militar. En Historia de las Fuerzas Militares de Colombia. Bogotá: Planeta.

Rueda Vargas, T. (1944). El Ejército Nacional. Bogotá: Librería Colombiana, Camacho Roldán y Editorial Antena.

Uribe, C. (1935). La verdad sobre la guerra. Bogotá: Editorial Cromos.

Valencia, A. (comp). (1996). Historia de las Fuerzas Armadas en Colombia. Bogotá: Editorial Planeta.

\section{Archivos consultados}

Archivo General de la Nación. Bogotá, Colombia. agn.

Archivo de la Presidencia de la República. Bogotá, Colombia. apr.
Archivo General del Ministerio de Defensa. Bogotá, Colombia. Anac.

Museo de la Escuela Militar de Cadetes. Bogotá, Colombia. memc.

\section{Prensa}

El Espectador. Bogotá, 1920-1930.

El Liberal. Bogotá, 1930.

El Nuevo Tiempo. Bogotá, 1922-1934.

El Siglo. Bogotá, 1920-1958.

El Tiempo. Bogotá, 1920-1930.

Este artículo presenta algunas inconsistencias en las referencias bibliográficas. En primer lugar, las referencias de prensa son muy amplias, es necesario presentar datos más concretos, sobre todo en un texto que nos muestra resultados de una investigación, en la cual, como se sabe, debe predominar cierta rigurosidad para este tipo de información.

Por otra parte, es necesario complementar las referencias citadas en las notas de pie de página 12 , $13,14,19,21,22,26,27,28,29,30,31,32,49$ y 50 , conforme con lo presentado en las demás notas, $\mathrm{o}$ presentar la información de manera que se ajuste al sistema APA para incluirla en las referencias y, así, poder citar en cuerpo de texto y suprimir las notas. 